Corrosion Science, 1993, Volume 35, Issues 1-4, Pages 19-25.

ISSN: 0010-938X

DOI: $10.1016 / 0010-938 X(93) 90128-4$

http://www.elsevier.com

http://www.elsevier.com/wps/find/journaldescription.cws_home/260/description\#description

http://www.sciencedirect.com/science/article/B6TWS-48W9RB9-6/2/8d398b271c9e92cde2ad5a31373a64ce

(C) 1993 Elsevier Ltd.

\title{
In Situ Studies of Passive Film Chemistry using X-ray Absorption Spectroscopy
}

\author{
Alison J. Davenport \\ Brookhaven National Laboratory \\ Jennifer A. Bardwell \\ Institute for Microstructural Studies National Research Council
}

Hugh S. Isaacs

Brookhaven National Laboratory

Barry MacDougall

Institute for Environmental Chemistry National Research Council

Gerald S. Frankel

IBM

\section{Alex G. Schrott}

IBM

\begin{abstract}
The passive film on sputter-deposited thin film $\mathrm{Fe}$ and $\mathrm{Fe}$-26Cr electrodes has been examined using in situ X-ray Absorption Near Edge Spectroscopy (XANES). During the x-ray spectroscopic measurements, samples were maintained under potentiostatic control in $\mathrm{pH} 8.4$ borate buffer. The passive film on both $\mathrm{Fe}$ and $\mathrm{Fe}-26 \mathrm{Cr}$ is formed from the metal without any detectable losses due to dissolution. Cathodic reduction leads to a loss of $\mathrm{Fe}$ from the film in both cases, but substantially less $\mathrm{Fe}$ is lost in the case of $\mathrm{Fe}-26 \mathrm{Cr}$. Transpassive dissolution of $\mathrm{Cr}$ from $\mathrm{Fe}-26 \mathrm{Cr}$ only occurred on the second potential cycle after the film had been enriched in $\mathrm{Cr}$ due to the reductive dissolution of Fe. Simultaneous collection of both the Fe and $\mathrm{Cr} \mathrm{X}-$ ray absorption edges provides quantitative information on the relative amounts of material lost during passivation and reduction.
\end{abstract}

\section{Introduction}

The chemistry of passive films formed on pure metals and alloys in aqueous electrolytes is the subject of much experimental investigation. Surface analytical work has been carried out using e.g. Auger, X-ray Photoelectron Spectroscopy (XPS) and Secondary Ion Mass Spectroscopy (SIMS), leading to a greater understanding of the composition of passive films. However, these measurements must be made ex situ in UHV and it has been demonstrated ${ }^{1}$ that the passive film on $\mathrm{Fe}-\mathrm{Cr}$ alloys is not stable when removed from an aqueous environment for $e x$ situ examination. Thus, an in situ technique is to be preferred, particularly if it can yield detailed information about the composition and valence states of elements in the film. These requirements are met by in situ X-ray Absorption Spectroscopy ${ }^{2-4}$. In the present work, X-ray Absorption Near 
Edge Structure (XANES) has been used to study the passive films on $\mathrm{Fe}$ and $\mathrm{Fe}-26 \mathrm{Cr}$.

\section{Experimental}

The experimental setup for in situ XANES measurements has been described previously ${ }^{3}$ and is shown in Figure 1. The design of the cell ensured good potential control of the sample at all times. Potentials are quoted with respect to a saturated mercurous sulfate reference electrode $(\sim 0.4 \mathrm{~V}(\mathrm{SCE}))$. The electrolyte was a $\mathrm{pH} 8.4$ borate buffer. The solution was deaerated throughout the experiments by bubbling with nitrogen which also ensured that all dissolution products were removed from the vicinity of the electrode. The samples consisted of a $6 \mu \mathrm{m}$ Mylar film onto which $\sim 100 \AA$ of $\mathrm{Nb}$ or Ta were sputtered to provide electrical contact. 20 or $40 \AA$ of the alloy under investigation ( $\mathrm{Fe}$ or $\mathrm{Fe}-26 \mathrm{Cr}$ ) was then deposited on top of the conducting layer. Measurements were made at Beamline X19A at the National Synchrotron Light Source. Data were collected in fluorescence geometry using a 13-element solid state detector (Canberra).

A set of absorption edges of standard compounds of known valency were measured in transmission geometry. The compounds were ground finely and sealed in adhesive Kapton tape. Absorption edges of metallic chromium and iron were collected from thin metal foils, also measured in transmission

\section{Results and Discussion}

A series edges of $\mathrm{Cr}$ and $\mathrm{Fe}$ standard compounds is shown in Figures 2 and 3 respectively. In general the absorption edge moves to higher energy as the oxidation state of the metal increases. The spectra of $\mathrm{Fe}$ and $\mathrm{Cr}$ both show relatively flat features after the edge, where the spectra for $\mathrm{Fe}_{3} \mathrm{O}_{4}, \mathrm{Fe}_{2} \mathrm{O}_{3}$ and $\mathrm{Cr}_{2} \mathrm{O}_{3}$ show a sharp peak. The 6-valent $\mathrm{Cr}$ shows a distinctive pre-edge peak. These characteristics can be used to easily visualize the changes in oxidation state in a sample containing a particular element in more than one valence state.

Figure 4 shows a series of spectra collected at the iron $K$ edge from a $40 \AA$ film of iron polarized cyclically in a borate buffer. It should be noted that the edges are not normalized so changes in the edge height represent quantitative changes in the amount of iron present. The initial curve was collected after cathodic reduction of the air-formed oxide film at $-1.5 \mathrm{~V}$. The edge position and flat top to the edge is characteristic of metallic iron. On stepping the potential to $-0.4 \mathrm{~V}$ and then to $+0.4 \mathrm{~V}$, the edge position shifts to higher energies and the top of the edge begins to sharpen into a peak (both are characteristic of oxides). The height of the edge at the right hand side of the figure does not change indicating that in the solution used (a borate buffer), oxidation of iron proceeds by a solid state reaction without any detectable dissolution. Reduction of the passive film on stepping the potential back to $-1.5 \mathrm{~V}$ results in a spectrum identical in shape to the first one, but the drop in the edge height indicates the dissolution of a significant amount of iron. Spectra from the next cycle show that this process is repeatable a second time. Subsequent cycles do not show such clear behavior, probably due to a loss of integrity of the very thin film. The loss of material during reduction suggests that the 3 -valent oxide is reduced to the soluble 2-valent state which dissolved away leaving a bare metal surface. If this reductive dissolution process were $100 \%$ efficient, then it should be possible to reconstruct the XANES signal originating from the oxide alone by subtracting curve (d) from curve (c). The result of this subtraction is shown as (1). Its shape is characteristic of 3-valent iron oxides (2) but the negative deviation in the curve around $7120 \mathrm{eV}$ indicates that $\mathrm{Fe}$ in the metallic state has been gained upon cathodic reduction. Approximate fitting of this curve indicates that the ratio of reductive dissolution to solid state reduction is in the region of $2: 1$. 
The total amount of metal lost in each potential cycle is listed in Table 1. It is calculated on the following basis: it is assumed that the height of the Fe $K$ edge for the as-deposited sample (which has a very thin air-formed oxide film), not shown, corresponds to $40 \AA$ of iron. If, for example, the edge height drops by $20 \%$, this corresponds to a loss of iron equivalent to $8 \AA$ of metal. From Table 1, it appears that each potential cycle for pure iron involves the loss of approximately $7 \AA$.

A similar set of experiments was carried out for thin films of $\mathrm{Fe}-26 \mathrm{Cr}$. One of the advantages of using a multi-element solid state detector is that different detector elements can be used to collect fluorescence data from different chemical elements. Thus iron and chromium $K$ edges can be collected by scanning over both edges in a single spectrum whilst different detector elements collect $\mathrm{Fe} \mathrm{K}_{\alpha}$ and $\mathrm{Cr} \mathrm{K}_{\alpha}$ fluorescent photons. Figure 5(a) shows details of the $\mathrm{Fe}$ edge in a polarization experiment on $\mathrm{Fe}-26 \mathrm{Cr}$. The results are qualitatively similar to those found for pure iron: metallic Fe present at $-1.5 \mathrm{~V}$ undergoes oxidation at $-0.4 \mathrm{~V}$ and $+0.4 \mathrm{~V}$ without any loss of material, then undergoes significant dissolution as the sample is reduced back to $-1.5 \mathrm{~V}$. This behavior is repeated on a second potential cycle (not shown). However, the amount of iron lost in each cycle is $\sim 2 \AA$, considerably less than the $\sim 7 \AA$ lost in the case of pure iron.

The chromium $K$ edge, measured during the same two potential cycles, is shown in Figure 5(b). Whilst the data are noisy due to the low concentration of chromium and the diminished number of detector elements used, it is clear that the data fall into two bands. All the spectra are roughly similar in shape, but there is a significant loss of chromium indicated by a drop in the edge height during the second potential cycle when the potential is raised into the transpassive region (increased from $-0.4 \mathrm{~V}$ to $+0.4 \mathrm{~V}$ ). Concurrent monitoring of the iron and chromium edges demonstrates the interplay between the two elements in the film: on the first potential cycle, both elements are oxidized into the film. However, chromium is not present in the film in a sufficient concentration for significant transpassive dissolution to take place. During reduction of the oxide at the end of the first potential cycle, iron is lost by reductive dissolution leading to enrichment of chromium in the passive film. On the second potential cycle, the chromium is now no longer protected by the iron and is present in a sufficient concentration or transpassive dissolution to occur. This model is consistent with similar work carried out on $\mathrm{AlCr}$ alloys ${ }^{5}$. In the presence of a protective alumina layer, chromium is trapped in the film but if the alumina dissolves, then transpassive dissolution of chromium can take place.

Cyclic voltammograms of the thin film $\mathrm{Fe}$ and $\mathrm{Fe}-26 \mathrm{Cr}$ electrodes were similar to those for bulk electrodes (after the second cycle in the case of $\mathrm{Fe}-26 \mathrm{Cr}$ ) indicating that the electrochemistry is not affected by the thinness of the sample.

In situ X-ray absorption spectroscopy is thus a powerful technique for studying alloy passivation. In addition to providing in situ valency information, the approach allows sensitive measurement of the quantity of material lost from the alloy through dissolution or passivation. In principle, it is possible to determine which components of an alloy undergo selective dissolution, which are enriched in the passive film, and which are enriched under the film in the metallic state.

\section{Conclusions}

1. Formation of the passive film on both iron and $\mathrm{Fe}-26 \mathrm{Cr}$ proceeds without any metal dissolution.

2. Cathodic reduction of the passive film on iron leads to the loss of the equivalent of $\sim 7 \AA$ of metal in dissolution. The ratio of reductive dissolution to solid state reduction is 
approximately in the region of $2: 1$.

3. Cathodic reduction of the passive film on Fe-26Cr leads to the loss of only $-2 \AA$ of iron.

4. Transpassive dissolution of chromium from $\mathrm{Fe}-26 \mathrm{Cr}$ can only take place on the second potential cycle once iron in the film has undergone reductive dissolution leading to enrichment of chromium in the passive film.

5. In situ x-ray absorption spectroscopy of passive films on thin film electrodes is an excellent technique for obtaining quantitative data on valency and dissolution during alloy passivation.

\section{Acknowledgement}

This work was performed in part under the auspices of the U.S. Department of Energy, Division of Materials Sciences, Office of Basic Energy Science under Contract No. DE-AC02-76CH0OO16. Measurements were carried out at Beamline X19A at the National Synchrotron Light Source with help from Lars Furenlid. The authors would like to acknowledge the assistance of M. J. Graham and G. I. Sproule.

\section{References}

1. J. A. Bardwell, G. I. Sproule, D. F. Mitchell, B. MacDougall and M. J. Graham, J. Chem. Soc. Farad. Trans. 87, 1011 (1991).

2. M. Kerkar, J. Robinson and A. J. Forty, Farad. Discuss. Chem. Soc. 89, 31 (1990).

3. A. J. Davenport, H. S. Isaacs, G. S. Frankel, A. G. Schrott, C. V. Jahnes and M. A. Russak, J. Electrochem. Soc. 138, 337 (1991).

4. J. A. Bardwell, G. I. Sproule, B. MacDougall, M. J. Graham, A. J. Davenport and H. S. Isaacs, J. Electrochem. Soc. 139, 371 (1992).

5. A. J. Davenport, H. S. Isaacs, G. S. Frankel, A. Schrott, C. V. Jahnes, and M. A. Russak, submitted to J. Electrochem. Soc.

Table I. Amount of metal lost during potential cycling measured from the edge height and converted into an equivalent thickness of pure metal.

\begin{tabular}{|c|c|c|c|c|}
\hline edge measured & sample & $\begin{array}{l}\text { sample thickness } \\
\qquad A\end{array}$ & cycle & $\begin{array}{l}\text { metal lost } \\
\quad / \mathcal{A} \\
\pm 1\end{array}$ \\
\hline \multirow[t]{9}{*}{$\mathrm{Fe}$} & \multirow[t]{3}{*}{$\mathrm{Fe}$} & \multirow[t]{3}{*}{40} & 1 & 8 \\
\hline & & & 2 & 6 \\
\hline & & & 3 & 2 \\
\hline & \multirow[t]{2}{*}{$\mathrm{Fe}$} & \multirow[t]{2}{*}{20} & 1 & 7 \\
\hline & & & 2 & 2 \\
\hline & \multirow[t]{2}{*}{$\mathrm{Fe}-26 \mathrm{Cr}$} & \multirow[t]{2}{*}{40} & 1 & 2 \\
\hline & & & 2 & 2 \\
\hline & \multirow[t]{2}{*}{$\mathrm{Fe}-26 \mathrm{Cr}$} & \multirow[t]{2}{*}{20} & 1 & 1 \\
\hline & & & 2 & 3 \\
\hline \multirow[t]{6}{*}{$\mathrm{Cr}$} & \multirow[t]{2}{*}{$\mathrm{Fe}-26 \mathrm{Cr}$} & \multirow[t]{2}{*}{40} & 1 & 0 \\
\hline & & & 2 & 2 \\
\hline & \multirow[t]{2}{*}{$\mathrm{Fe}-26 \mathrm{Cr}$} & \multirow[t]{2}{*}{20} & 1 & 0 \\
\hline & & & 2 & $>3^{+}$ \\
\hline & \multirow[t]{2}{*}{$\mathrm{Fe}-26 \mathrm{Cr}$} & \multirow[t]{2}{*}{40} & $1^{*}$ & 3 \\
\hline & & & 2 & 2 \\
\hline
\end{tabular}

"Sample was "activated" by stepping to $+0.8 \mathrm{~V}$ and back down to $-1.5 \mathrm{~V}$

†'Sample sat in the transpassive region for several hours due to problems with the synchrotron. 


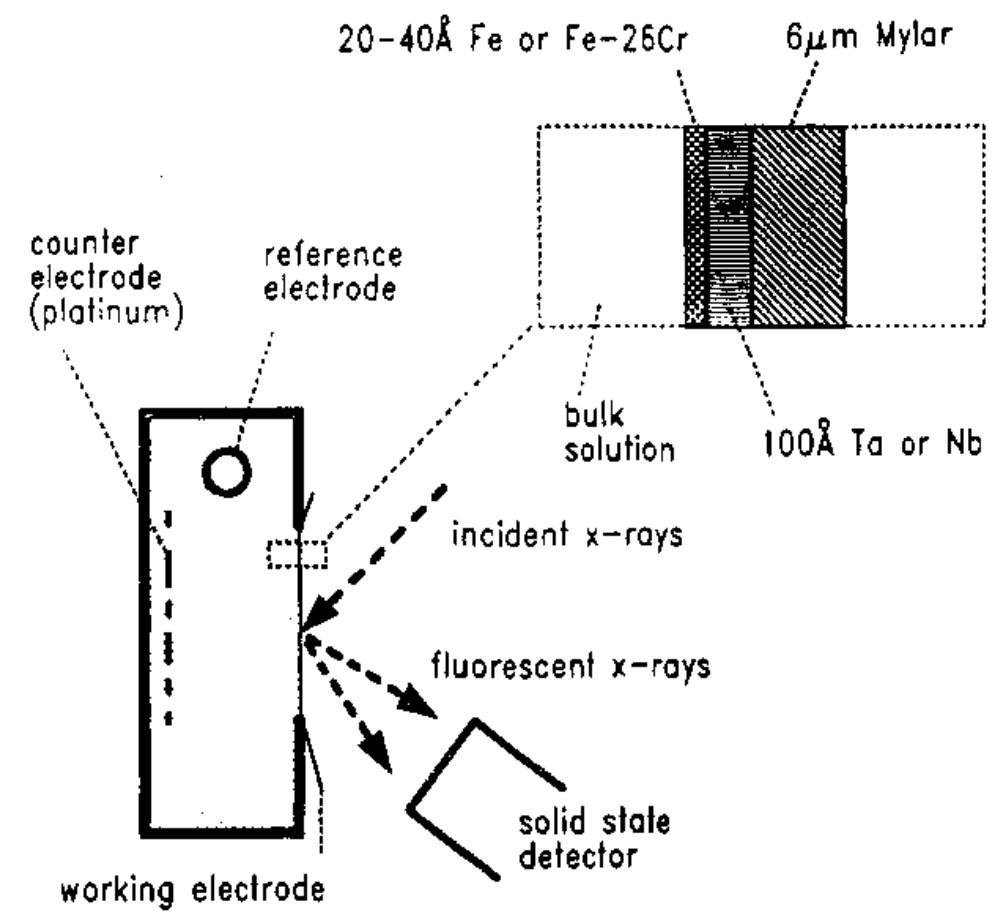

Figure 1. Experimental setup for in situ XANES measurements

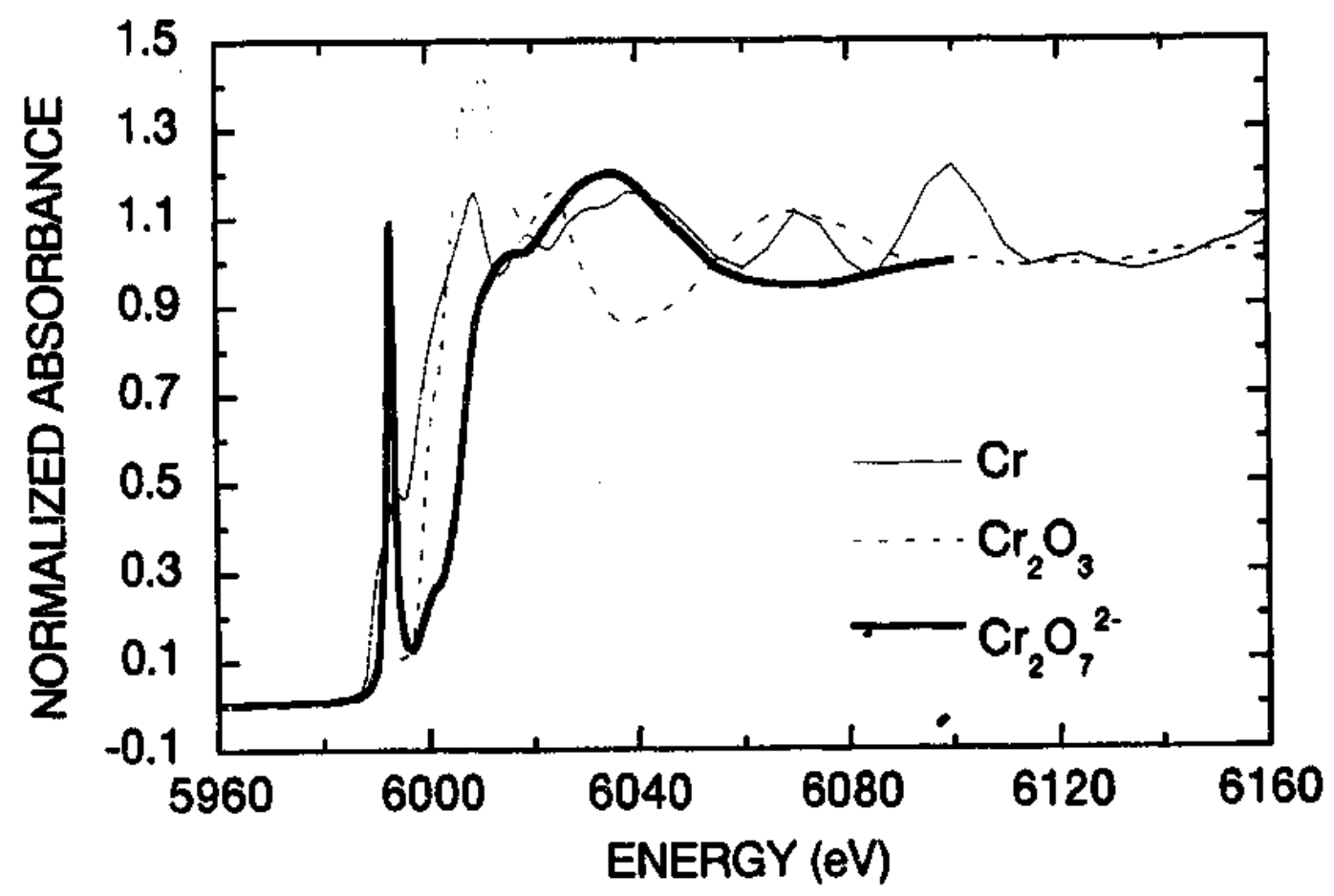

Figure 2. Cr $K$ edges of standard compounds measured in transmission. 


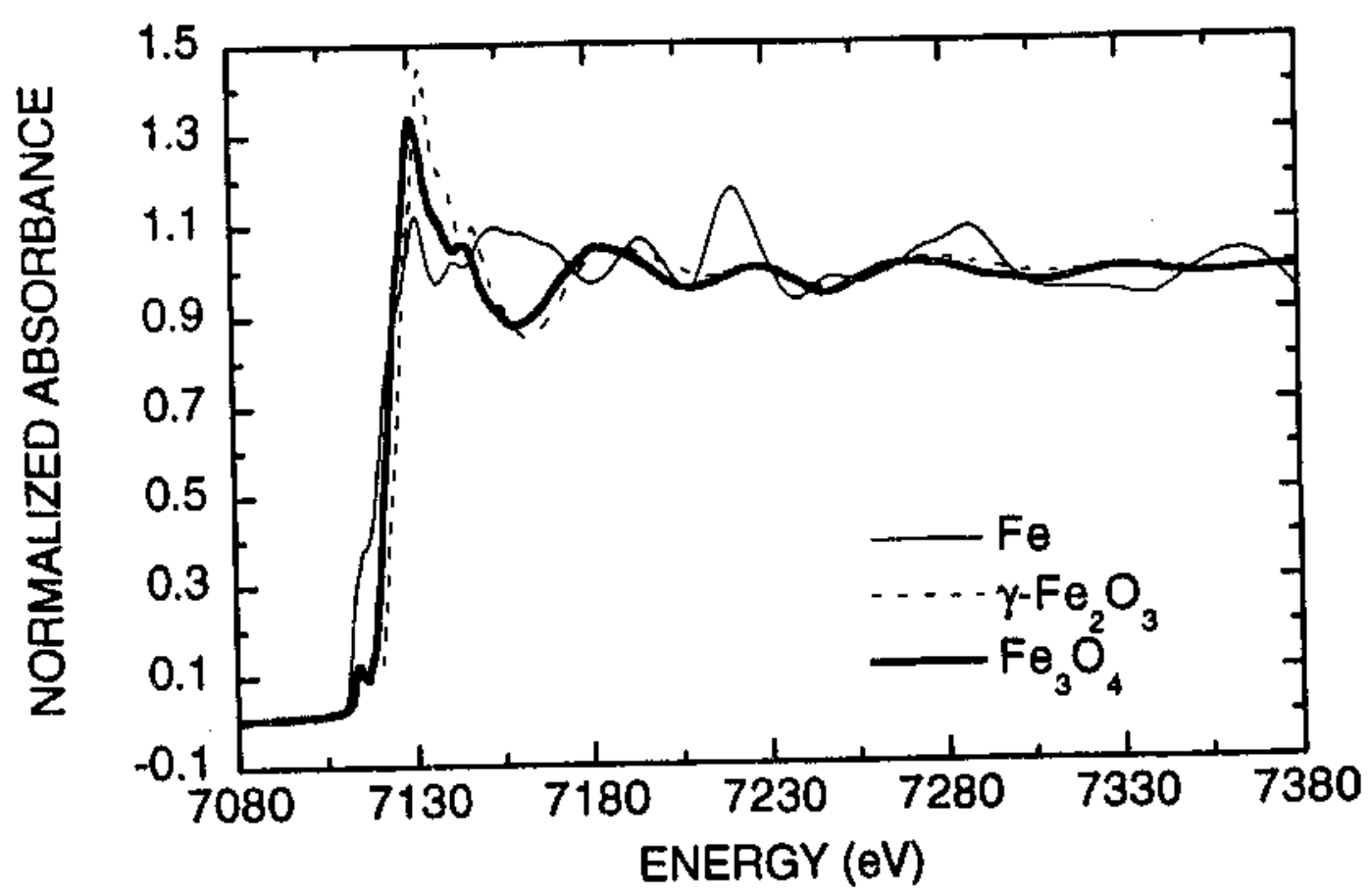

Figure 3. Fe $K$ edges of standard compounds measured in transmission.

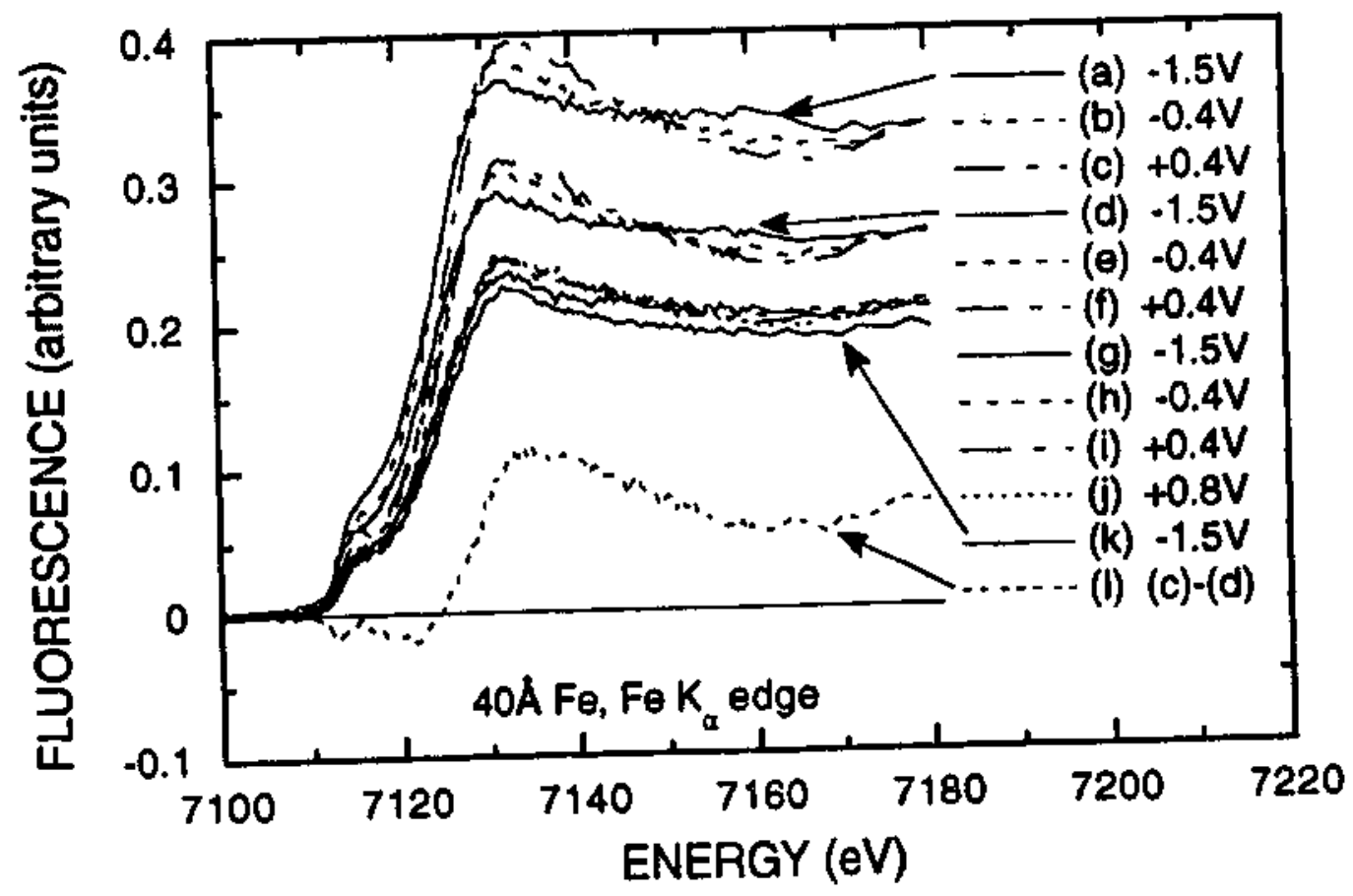

Figure 4. Fe $K$ edge of $40 \AA$ of Fe on $100 \AA$ of Ta. The spectra were recorded on stepping the potential in the sequence indicated. Curve (1) is the difference between (c) and (d). 
(a)

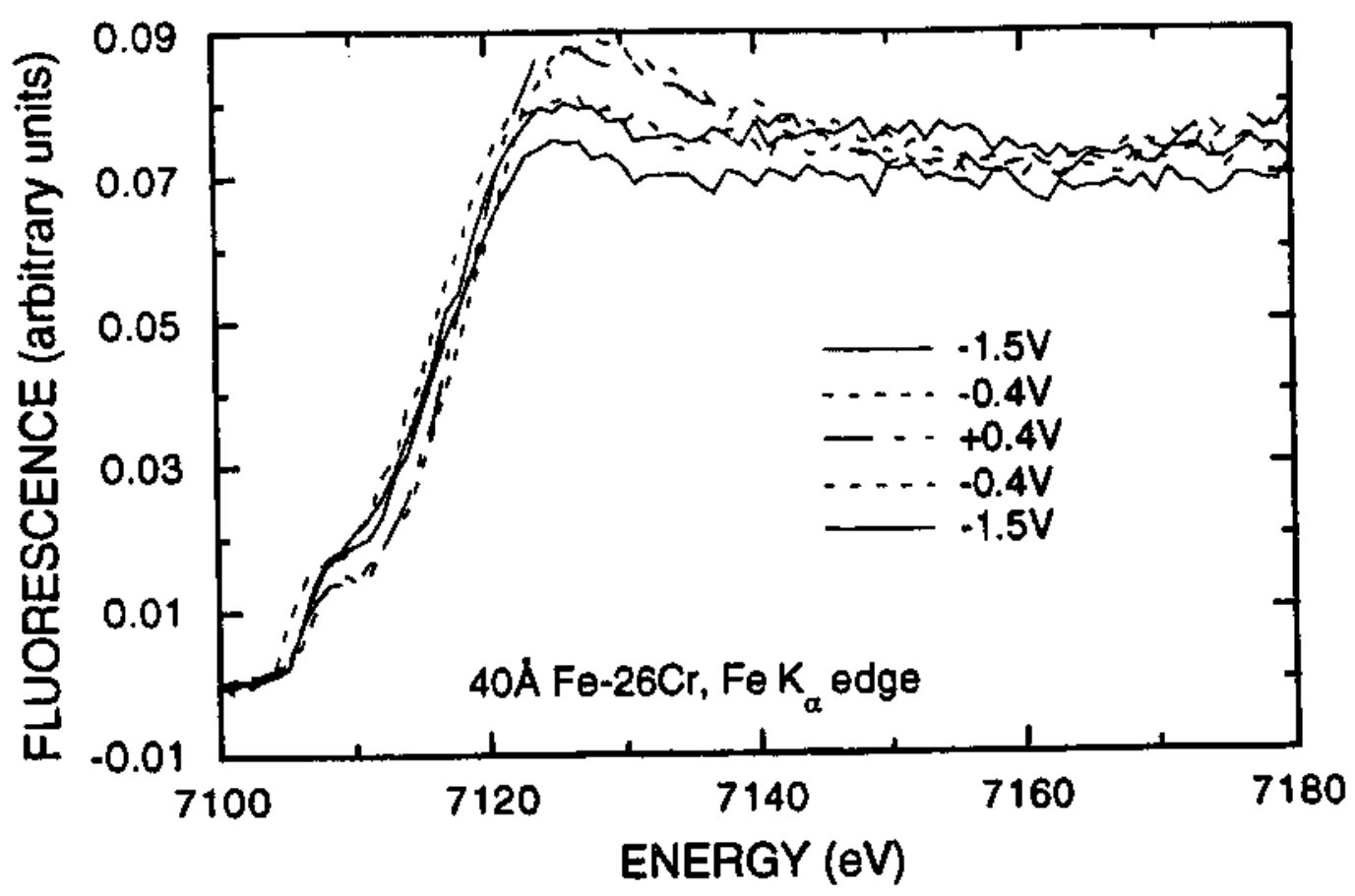

(b)

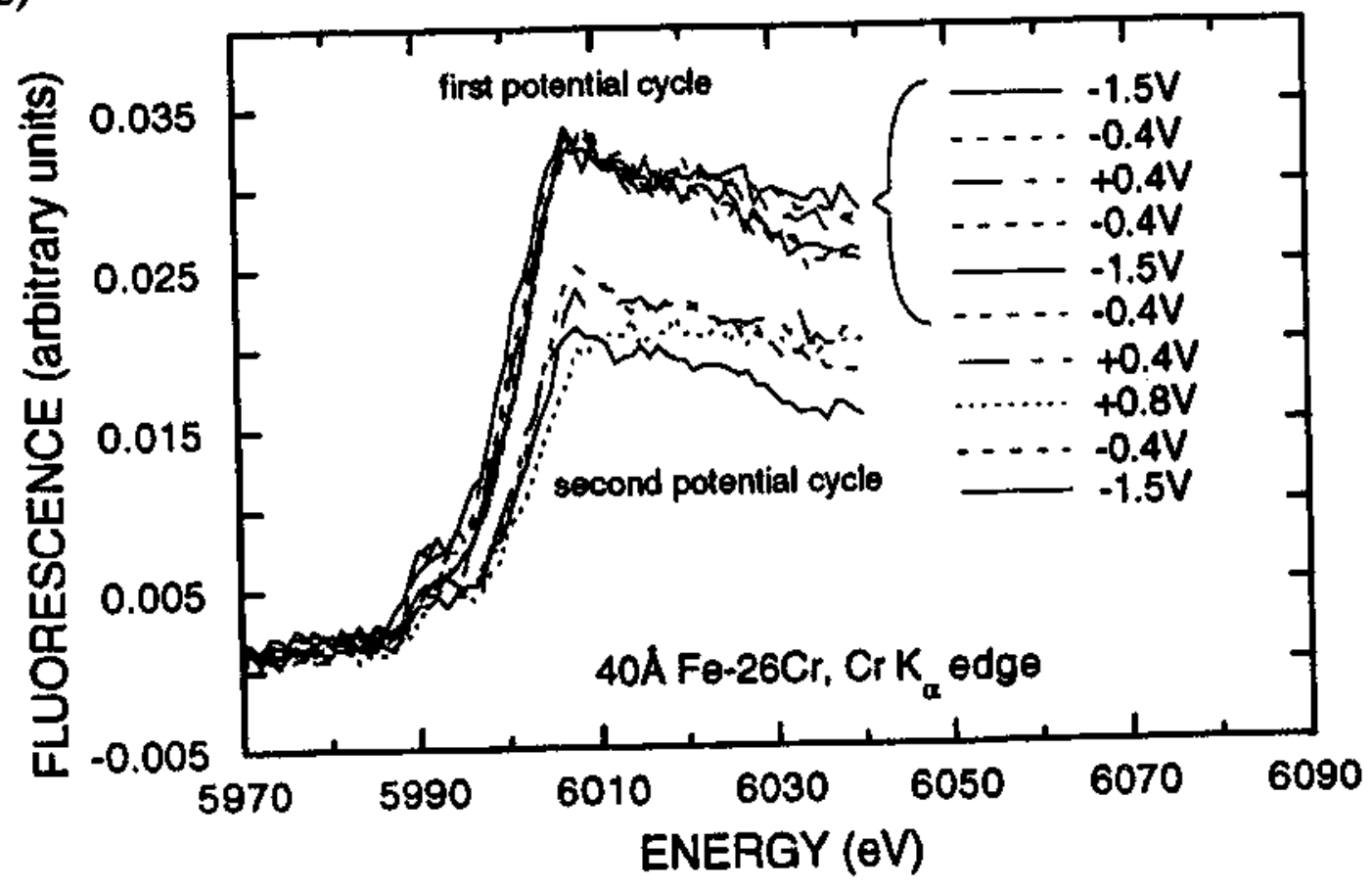

Figure 5. $40 \AA$ of $\mathrm{Fe}-26 \mathrm{Cr}$ stepped through two oxidation/reduction cycles with the potential sequence indicated: (a) Fe $K$ edge (only the first potential cycle is shown); (b) $\mathrm{Cr} K$ edge. 